Kasereka KAVWAHIREHI, «De la négritude à la migritude», @nalyses, printemps 2007

\title{
Kasereka KAVWAHIREHI
}

\section{De la négritude à la migritude}

Encore jeune, comme d'aucuns aiment à le rappeler, la littérature francophone d'Afrique noire ne se présente pas moins déjà comme un labyrinthe dans lequel le nouveau venu non pourvu d'un fil d'Ariane pourrait bien se perdre. La seule question de la coexistence chez les critiques de l'usage du singulier (littérature francophone d'Afrique noire) et du pluriel (littératures francophones d'Afrique noire) peut donner un avant-goût des difficultés qui peuvent se poser au nouvel arpenteur de ce champ en pleine effervescence et expansion. À cela, il faudrait ajouter les poncifs à la mode, tels que «nouvelles écritures» promues par une «nouvelle génération» d'écrivains africains, le problème étant que ce n'est pas toujours avec bonheur que ceux qui les lancent arrivent à circonscrire, avec précision, les contours ou les critères définitoires d'une génération littéraire en dehors des considérations d'ordre sociologique. En effet, un écrivain ayant entamé sa carrière avec la négritude peut aujourd'hui partager bien des choses, en termes d'esthétique/poétique, de thématique et même de vision du monde, avec ceux qu'on appelle les écrivains de la «migritude» ou «négropolitains », lesquels semblent constituer la «nouvelle génération» ainsi qu'en parle, par exemple, Odile Cazenave en mettant en avant le paramètre topologique. Un regard sur le parcours littéraire d'un auteur comme Henri Lopes depuis Sans tamtam, au parfum nationaliste, jusqu'à Dossier classé, qui semble faire éclater les vieilles certitudes liées par exemple à la quasi-mystique de la "terre natale», de la Nation ou à l'idée d'une identité et d'une esthétique "nègres", est fort éloquent à ce sujet. Au lieu de parler de nouvelle génération littéraire, peut-être devrait-on parler de nouvelle conscience littéraire.

C'est pour parer aux difficultés de ce genre que Jacques Chevrier semble avoir écrit Littératures francophones d'Afrique noire. En effet, dans 
Kasereka KAVWAHIREHI, «De la négritude à la migritude», @nalyses, printemps 2007

cet ouvrage, qui est manifestement destiné à supplanter le précédent, à savoir Littérature nègre (1984) - les changements dans les intitulés sont à noter - , le critique africaniste français retrace les principales étapes de l'histoire des lettres francophones d'Afrique noire, des origines jusqu'à nos jours. Il s'efforce, en suivant un ordre chronologique et en s'arrêtant sur "les œuvres jugées les plus marquantes », d'en dégager "les tendances esthétiques et thématiques dominantes et les principaux acteurs » (p. 6), sans oublier l'ancrage dans l'histoire sociale et politique du continent. En effet, dans sa mise en perspective des littératures francophones d'Afrique noire, Jacques Chevrier tient à reconstituer les contextes géographiques, historiques, culturels et même économiques, lesquels sont, selon lui, «de nature à faciliter l'approche d'une littérature africaine aujourd'hui en pleine expansion » (p. 6).

Le livre nous offre ainsi l'histoire d'une littérature qui semble intimement liée à la situation sociale, culturelle, politique et économique de sa production. Il est possible d'y lire en filigrane l'idée d'une littérature fortement engagée. Ce sont les vicissitudes de l'histoire coloniale et postcoloniale qui structurent le livre dans sa majeure partie, reléguant la partie la plus intéressante, «L'aventure des écritures ", à la toute dernière partie. Après la première partie, consacrée aux repères historiques, politico-économiques et culturels (p. 7-34), le lecteur compte huit parties, dont les principaux angles d'attaque sont les suivants : la situation coloniale qui a suscité le grand courant de la négritude, "les temps des indépendances » caractérisés par des «illusions perdues », le « goulag tropical», l'errance et la prise de parole des femmes, les temps des indépendances trahies qui ont précipité et (re)plongé l'Afrique « au cœur des ténèbres » de la violence absurde et fait naitre chez les jeunes la désaffection envers le "pays natal» et le rêve d'un voyage sans retour en Occident (la migritude). Ce dernier angle d'attaque donne des chapitres comme ceux-ci : «Un monde de violence», "L'écriture du génocide», "L'écriture de la guerre », «De la négritude à la migritude» ou encore "Afrique-surSeine ou l'impossible retour ». 
Kasereka KAVWAHIREHI, «De la négritude à la migritude», @nalyses, printemps 2007

Poussée jusqu'aux limites de sa logique, cette manière de mettre en perspective les littératures africaines en arrimant leur développement aux vicissitudes des situations sociales ou politiques du continent pourrait susciter quelques objections. En effet, on ne saurait dire que ce sont les situations politiques ou sociales qui fondent les «mutations », les « ruptures» dans le discours littéraire africain sans minoriser son autonomie ou, si l'on préfère, les questions relatives à la littérarité et aux choix esthétiques personnels des auteurs en dehors de tout déterminisme socio-historique. Les mutations esthétiques au cœur du roman africain depuis Camara Laye, Mongo Beti et Bernard Dadié jusqu'à Alain Mabankou et Fatou Diome, en passant par Yambo Ouloguem, Georges Ngal, Sony Labou Tansi, Werewere Liking et Calixthe Beyala dépassent la simple loi d'homologie avec la situation ou condition de production. L'écrivain africain se lance aussi dans l'exploration des ressources du «verbe » ou dans ce que l'auteur luimême appelle les «aventures de l'écriture ». Comme le disait Roland Barthes, "la littérature est [à la fois] signe d'histoire et résistance à l'histoire $»^{1}$.

Cependant, il sied de souligner que cet ouvrage qui accorde une place aux œuvres les plus récentes n'est pas sans originalité. Alors que la plupart des monographies sur les littératures francophones d'Afrique sont généralement consacrées à la prose romanesque, l'ouvrage de Jacques Chevrier a l'heureuse ambition d'embrasser non seulement le roman, mais aussi le théâtre et la poésie. Il aurait donc pu se construire autour de ces trois genres, mais peut-être fallait-il éviter un déséquilibre trop criant. En effet, sur les 203 pages que comprend le livre, 20 pages seulement sont consacrées à la poésie et au théâtre, qui apparaissent ainsi comme les parents pauvres de la littérature africaine. De plus, un regard jeté sur « l'orientation bibliographique » proposée à la fin de l'ouvrage confirme l'insatisfaction du lecteur quant à ce qui concerne la place réservée à la poésie et au théâtre. En effet, on a l'impression qu'après les années 1970, il ne s'est pas produit de textes dramatiques ou poétiques à recommander au lecteur. Faut-il penser

${ }^{1}$ Cité par Éric Méchoulan, Pour une histoire esthétique de la littérature, Paris, PUF, 2004, coll. «L'interrogation philosophique », p. 20. 
Kasereka KAVWAHIREHI, «De la négritude à la migritude», @nalyses, printemps 2007

que les temps du «goulag tropical » n'ont guère «produit» de poètes et de dramaturges? La réponse à cette question tient sans doute à l'orientation choisie par l'auteur, à savoir la tradition des "chefsd'œuvre » (les « œuvres marquantes » des "principaux acteurs»), sans oublier l'ancrage parisien du regard jeté sur les littératures francophones d'Afrique noire. Ainsi, on n'a presque pas d'écho de la littérature africaine locale, celle produite en dehors des maisons d'édition parisiennes.

Enfin, ce qui frappe le plus dans le livre de Jacques Chevrier comme dans plusieurs livres qui présentent les littératures francophones d'Afrique noire, c'est l'absence d'une séquence consacrée à la nouvelle et, plus particulièrement, à l'essai. En effet, tout se passe assez souvent comme si parler de littératures francophones d'Afrique noire, c'est parler de la prose narrative, ou encore comme si la prose d'idée n'avait pas sa place dans cette littérature. L'absence d'une partie consacrée à l'essai est assez paradoxale dans la mesure où, dans la séquence intitulée «La négritude contestée », qui clôt l'important chapitre consacré à la négritude, l'auteur reconnaît que « ce chapitre [...] serait incomplet s'il n'évoquait tout un pan de la production littéraire africaine consacrée à des ouvrages qui relèvent des sciences humaines, et dont le nombre n'a cessé de se multiplier» (p. 73). Et de citer Négritude ou servitude (1971) de Martien Towa, Négritude et Négrologues (1972) de Stanislas Adotevi, Les dirigeants africains face à leur peuple (1964) de Seydou Badian, Le double d'bier rencontre aujourd'bui (1973) de Boubou Hama, Sur la philosophie africaine (1977) de Hountondji et L'Autre face du Royaume (1973) de V.Y. Mudimbe. Il faudrait sans doute ajouter La crise du Muntu. Authenticité africaine et philosophie d'Eboussi Boulaga, qui joue allégrement de l'ironie et du pastiche et qui me semble, du point de vue de l'écriture, un des plus beaux essais africains de cette période. On pourrait dire la même chose des chapitres consacrés au temps «des illusions perdues » et des «[a]mertumes et espérances contemporaines » en considérant des essais comme L'Afrique va-telle mourir? Bousculer l'imaginaire africain (1991) de Kä Mana, L'Afrique a-t-elle besoin d'un programme d'ajustement culturel? (1991) de Daniel Etounga Manguelle, Et si L'Afrique refusait le développement? (1991) de Axelle Kabou, sans oublier L'Afrique malade d'elle-même (1986) de Tidiane 
Kasereka KAVWAHIREHI, «De la négritude à la migritude», @nalyses, printemps 2007

Diakite, qui semblent eux aussi faire «un bilan de faillite » africaine (p. 75).

Malgré ces faiblesses, le livre de Jacques Chevrier reste un outil utile pour une initiation aux littératures francophones d'Afrique, surtout pour le lecteur à qui il l'a lui-même destiné, à savoir le «lecteur peu familier de l'Afrique » (p. 6). Ce qui justifie la démarche adoptée, celle de lier l'écriture au contexte de sa production. Démarche qui ne manque pas de cohérence. En définitive, posant des balises pour indiquer au lecteur intéressé les grandes avenues, ce livre témoigne de la maitrise que l'auteur possède des littératures francophones d'Afrique qui, à en croire Chevrier, semblent aujourd'hui se situer entre deux positions : celle de la négritude senghorienne - avec son esthétique de la noblesse célébrant le pays natal — et l'esthétique de l'obscène ou de la dérision.

Référence : Jacques Chevrier, Littératures francophones d'Afrique noire, Aix-en-Provence, Édisud, coll. «Les Écritures du Sud », 2006, 212 pages. 